\title{
Aligning Sowing Dates with the Onset of Rains to Improve Rice Yields and Water Productivity: Modelling Rice (Oryza sativa L.) Yield of the Maha Season in the Dry Zone of Sri Lanka
}

\author{
R.P.R.K. Amarasingha*, L.W. Galagedara ${ }^{1}$, B. Marambe $^{2}$, G.L.L.P. Silva ${ }^{3}$ \\ R. Punyawardena ${ }^{4}$, U. Nidumolu ${ }^{5}$, M. Howden ${ }^{6}$ and L.D.B. Suriyagoda ${ }^{2}$ \\ Postgraduate Institute of Agriculture \\ University of Peradeniya \\ Sri Lanka
}

\begin{abstract}
Rice (Oryza sativa L.) cultivation in Sri Lanka is restricted by limited water availability. Increased variability of seasonal rainfall as a result of climate change will further exacerbate risk in rice cultivation. Knowing the onset of rainfall through forecasts, adjusting planting date based on the predicted rainfall onset, and efficient irrigation management are important determinants to reduce the risk in rice farming. In this study, a modelling approach was used to assess the yield advantage of changing planting dates according to the onset of seasonal rainfall compared to a fixed planting date in the major rainy season (Maha), and evaluated the efficiency of irrigation management. The model, Agricultural Production Systems Simulator (APSIM), was parameterized using data from the literature, and the model could simulate the observed yield of rice varieties Bg300 and Bg359 with a good fit $(C V<14 \%)$. Simulations carried out for Bg300, the rice variety that has recorded the largest extent of cultivation in Sri Lanka, revealed that changing the planting date according to the onset of rainfall can reduce the irrigation water requirement and yield loss. Early onset coupled with early planting resulted in an average yield of $3900 \pm$ $150 \mathrm{~kg} / \mathrm{ha}$, which was $33 \%$ higher than that of late planting with the same onset. Late onset coupled with late planting resulted in an average yield of $(3930 \pm 200 \mathrm{~kg} / \mathrm{ha})$, which was $34 \%$ higher than that of early planting with a late onset. Moreover, late planting at a late onset resulted in a higher variability in water productivity $(4.3 \pm 0.34 \mathrm{~kg} / \mathrm{ha} / \mathrm{mm})$ when compared to an early planting at an early onset $(4.4 \pm 0.12 \mathrm{~kg} / \mathrm{ha} / \mathrm{mm})$, even though the mean water productivity was similar. Therefore, timing of rice planting should be adjusted based on the forecast of the onset of seasonal rainfall to harness the maximum potential of available natural resources.
\end{abstract}

Keywords: APSIM, onset of rainfall, planting date of rice, seasonal climate forecast, waterproductivity

\footnotetext{
Department of Agricultural Engineering, Faculty of Agriculture, University of Peradeniya, Sri Lanka

Department of Crop Science, Faculty of Agriculture, University of Peradeniya, Sri Lanka

Department of Animal Science, Faculty of Agriculture, University of Peradeniya, Sri Lanka

Natural Resource Management Centre, Department of Agriculture, Peradeniya, Sri Lanka

Ecosystems Sciences, Commonwealth Scientific and Industrial Research Organization (CSIRO), Australia

6 Climate Adaptation Flagship, Commonwealth Scientific and Industrial Research Organization (CSIRO), Australia

* Corresponding author: ruwnga.amarasingha@gmail.com
} 


\section{INTRODUCTION}

Rice (Oryza sativa L.) is the staple food for Sri Lankans and is cultivated as a lowland crop in most parts of the country. The total land area devoted for rice cultivation is estimated to be around 708,000 ha (DCS, 2011). However, this total area is not cultivated in every season due to a number of reasons such as shortage of irrigation water during the growing season and delays in the onset of seasonal rains. In the major part of the island, rice is cultivated during Yala (rain from the first inter-monsoon from March-April and the south-west monsoon from May to August) and Maha (rain from the second inter-monsoon from September-October and the north-east monsoon from November-February) seasons.

Water scarcity occurs not only in Sri Lanka, but also in many parts of the world and is projected to be even in shorter supply in the future in some regions due to climate change (UNESCO-WWAP, 2009). This scarce resource is frequently wasted as a result of inefficient water management practices in agriculture (Thiyagarajan \& Selvaraju, 2001) resulting in low water productivity. Therefore, water-efficient agricultural practices are of immense importance to enable an increase in the area to be cultivated, and/or conserving water from rain to be used in the drier regions or seasons through irrigation.

Most of the paddy cultivation in Sri Lanka is practiced in the Dry and Intermediate Zones. The cultivation in Maha season is mainly under rainfed condition with supplementary irrigation, and in Yala season is mainly under irrigated condition. Rice growing areas can be classified into three categories based on the source of water supply, i.e. major and minor irrigation schemes and rainfed conditions. The average annual land area cultivated to rice using the major and minor irrigation schemes and under rainfed conditions are $47 \%, 25 \%$ and $28 \%$, respectively (DCS, 2011). In most of these areas, rice is established as broadcastsown crops using pre-germinated seeds in order to cut down labour costs and minimize water use. Water productivity could potentially be improved by commencing the rice cultivating season (i.e. land preparation and sowing) based on the onset of rains rather than adhering to a fixed calendar date that will use water from storage reservoirs during the initial stage. This adjustment would help to reduce the irrigation water requirement at the beginning of the cultivation season thus, saving water from reservoirs towards the end of the rice crop growth. This would enhance yield while reducing the cultivation risk in the Maha season. Moreover, unused and saved water in the reservoirs from the Maha rains could effectively and efficiently be used for rice cultivation in the subsequent Yala season. To implement this, there is a need for information on the onset of the rainfall season and shifts in rainfall patterns (i.e. access to seasonal climate forecasts). Whilst necessarily this information will be probabilistic because of various uncertainties around climate predictions, if sufficiently reliable and skilful, they could be potentially of great value leading to significant adaptation options such as adjusting planting dates and irrigation practices on an ongoing basis (McKeon et al., 1993).

Agricultural system simulation models could be useful tools to assess the performance of agricultural systems under different scenarios once carefully parameterized and validated. Resource requirements such as time, money and labour are lower for modelling approaches compared to the use of on-farm trials, allowing exploration of options that would not be possible using experimental-only approaches. The Agricultural Production Systems Simulator (APSIM; Keating et al., 2003) is a farming system modelling framework that simulates the effects of environmental variables and management decisions on production (crops, pasture, trees, and livestock), profits and system balance (e.g. soil condition). The model can be used to simulate the performances of different crops under diverse 
management decisions (e.g. irrigation management) and soil conditions. It can be used to analyze risks and explore alternative management options such as crop choice, planting date and fertilizer rate, using local climate and farm-specific soil data. When used interactively with farmers using appropriate engagement processes, the model can address some of the social and/or economic values or goals that influence an individual farmer's management decisions (http://www.apsim.info/Wiki/APSIM-Model.ashx).

The APSIM model is used around the world in a broad range of modelling applications, including supporting on-farm decision making, designing farming systems for production or resource-management objectives, assessing the value of seasonal climate forecasting, analyzing supply-chain issues in agri-business, developing waste-management guidelines and assessing risk for government policymaking (Keating et al., 2003). In Sri Lanka, it has been used to evaluate the nitrogen response of lowland rice (Suriyagoda \& Peiris, 2011) and to identify the optimum planting date for rainfed rice (Rathnayake \& Malaviarachchi, 2011).

The present study was conducted to; (i) estimate the APSIM-simulated potential yield (i.e. yield in the absence of moisture and nitrogen stresses, and pests and diseases occurrence) for short and medium duration rice varieties in the Dry Zone of Sri Lanka, (ii) assess the yield advantage when changing planting dates based on seasonal forecasts of the onset of rainfall compared to a fixed planting date in the Maha season, and (iii) evaluate the efficiency of irrigation management practices by changing the interval and volume of irrigated water.

\section{METHODOLOGY}

\section{Parameterization of rice module in APSIM}

The APSIM-ORYZA module in APSIM version 7.3 was used to parameterize the phenology and growth of rice varieties $\mathrm{Bg} 300$ (3 months age category) and $\mathrm{Bg} 359$ (3 1/2 months age category). Required data for these two varieties were collected from the available literature (Bouman et al., 2001; Rathnayake \& Malaviarachchi, 2011; Suriyagoda \& Peiris, 2011; Heinemann et al., 2012).

\section{Model testing and validation}

\section{Soil data}

Soil characteristics of the study area, Maha-Illuppallama in the North Central Province of Sri Lanka (agro-ecological region $\mathrm{DL}_{1 \mathrm{~b}}$, great soil group Low Humic Gley - LHG, Ketagal Ara series) were extracted from the available literature (Mapa et al., 2010) and are summarized in Table 1.

Table 1. Soil physical and chemical characteristics of the study area

\begin{tabular}{cccccccc}
\hline $\begin{array}{l}\text { Depth } \\
(\mathbf{c m})\end{array}$ & $\begin{array}{c}\text { Bulk } \\
\text { Density } \\
\left(\mathbf{g} / \mathbf{c m}^{3}\right)\end{array}$ & $\begin{array}{c}\text { Organic Carbon } \\
\text { (Walkley and } \\
\text { Black \%) }\end{array}$ & $\begin{array}{c}\mathbf{E C} \\
\mathbf{( 1 : 5} \\
\mathbf{m S / c m})\end{array}$ & $\begin{array}{c}\mathbf{p H} \\
\mathbf{( 1 : 5} \\
\text { water })\end{array}$ & $\begin{array}{c}\text { Sand } \\
(\boldsymbol{\%})\end{array}$ & $\begin{array}{c}\text { Silt } \\
(\boldsymbol{\%})\end{array}$ & $\begin{array}{c}\text { Clay } \\
(\boldsymbol{\%})\end{array}$ \\
\hline $0-35$ & 1.7 & 0.91 & 0.85 & 6.3 & 67 & 14 & 19 \\
$35-90$ & 1.5 & 0.2 & 0.30 & 6.6 & 55 & 10 & 35 \\
\hline
\end{tabular}




\section{Weather data}

Daily weather data (maximum and minimum temperatures, rainfall and sunshine hours) of 35 years from January 1976 to December 2011for Maha-Illuppallama were collected from the Natural Resource Management Center (NRMC) of the Department of Agriculture, Peradeniya, Sri Lanka. The daily incoming radiation $\left(\mathrm{MJ} \mathrm{m}^{-2}\right)$ for the study area was calculated using the sunshine hours and location specific information such as latitude $\left(8^{\circ} 08^{\prime}\right.$ $\left.50^{\prime \prime} \mathrm{N}\right)$ and longitude $\left(80^{\circ} 25^{\prime} 50^{\prime}\right.$ ' E), height above mean sea level $(137 \mathrm{~m})$, solar elevation (5), and Angstrom coefficients $(\mathrm{a}=0.29$ and $\mathrm{b}=0.39)$ (Samuel, 1991).

\section{Crop and management data}

The secondary data on planting date, time required from rice crop establishment (i.e. sowing) to flowering, 50\% heading and maturity, and yield were collected from the Field Crops Research and Development Institute (FCRDI) at Maha-Illuppallama using information from the National Coordinated Rice Variety Trials (NCRVT). Fertilizer and other management practices were identified according to the recommendations of the Department of Agriculture, Sri Lanka (http://www.agridept.gov.lk/index.php/en/croprecommendations/808). Planting dates and planting method (direct seeding), irrigation and fertilizer management strategies were adjusted in the model simulations as collected from the research station.

The APSIM-simulated potential (highest) yield is defined as the crop yield in the absence of moisture stress, nitrogen stress, and pest and diseases (http://www.apsim.info/Wiki/APSIMModel.ashx). In the simulation process, a maximum ponding depth of $8.0 \mathrm{~cm}$ of water was maintained in the field either through rainfall or irrigation. Irrigation was applied if rain was not received until when the ponding depth reduced to $1.0 \mathrm{~cm}$. Initial soil water content at the time of sowing was set to saturation. Nitrogen concentration (both $\mathrm{NO}_{3}^{-}$and $\mathrm{NH}_{4}^{+}$) was reset daily to maintain required concentrations to avoid nitrogen stress.

For the short age rice variety (Bg300) and medium age rice variety (Bg359), there were 13 and 9 observed yield datasets, respectively, from 1976 to 2011 in both Yala and Maha seasons at Maha-Illuppallama. The simulated phenology and yield using the site specific soil and weather data for Maha-Illuppallama were used to compare those with the observed values. Simulated and observed data were plotted on a 1:1 graph having an intercept of 0 and slope of 1 to identify the difference/similarity between the predicted and observed values for $\mathrm{Bg} 300$ and $\mathrm{Bg} 359$. The coefficient of variation (CV \%) and Root Mean Square Error (RMSE) were used as the statistical tools to compare the simulated and field measured data.

\section{Definition of scenarios modelled}

Advantage of adjusting crop establishment with the onset of rainfall than crop establishment on a fixed date (without irrigation):

The onset of rainfall is defined as a spell of at least 20-mm of rain per week in three consecutive weeks after a pre-specified week for the Maha (standard week 35). Once this requirement is fulfilled, the first week of the three consecutive weeks was considered as the onset of rainfall (Punyawardena, 2002; Chitranayana \& Punyawardena, 2010). If crop establishment is practiced by adjusting planting date based on the onset of rainfall rather than planting on a fixed calendar date, the hypothesis was that there would be a high possibility of 
using rain water more effectively and efficiently thus, reducing the dependency on irrigation. The rainfall data were analyzed from 1976 to 2011 and the onset date for the Maha season was identified for each year. Then the planting date was adjusted accordingly and four planting dates identified through the analysis were $11^{\text {th }}$ October, $25^{\text {th }}$ October, $1^{\text {st }}$ November, and $15^{\text {th }}$ November. Planting on the $1^{\text {st }}$ November is considered as the fixed date of planting. For the identified planting dates in respective years, simulations were run considering rainfall as the only water source (i.e. without supplementary irrigation), and without nitrogen stress.

Under rainfed conditions, farmers in Sri Lanka generally use short age rice varieties such as Bg300 to minimize the risk of rice farming as recommended by the Department of Agriculture; due to that it ensures a reasonable yield even if the onset of rainfall is delayed. Therefore, in the scenario analysis, the relative performance of the short age rice variety (i.e. $\mathrm{Bg} 300)$ in a variable planting date based on the onset of rainfall was compared with a fixed date of planting ( $1^{\text {st }}$ November), even if the model could predict yields of both the short and medium age rice varieties.

Evaluation of different irrigation management options, which maximize the water productivity (with irrigation):

This simulation was performed for two scenarios as an early planting (Oct-11) with an early onset and late planting (Nov-15) with a late onset. A set of simulations was tested by changing the irrigation water depths (i.e. above ground pond depth in APSIM as 5, 10 and 15 $\mathrm{cm}$ at a single irrigation event), and irrigation intervals (i.e. 5, 10 and 15 days). In these simulations, irrigation was applied only if the ponding water level could not be maintained through the rainfall. Even though the irrigation at fixed-day intervals are easy to manage, the ideal time to irrigate would be when the soil water content is depleted closer to the lower limit of the plant available water content. Therefore, one other irrigation option was tested by applying $5 \mathrm{~cm}$ of irrigation water when $75 \%$ of the plant available water content (i.e. the difference between the field capacity and the permanent wilting point) depleted in the root zone (SW). Those simulations were compared with the APSIM-simulated potential yield (i.e. no moisture and nitrogen stresses) and yield without irrigation (WI). Results were used to calculate the water productivity for $\mathrm{Bg} 300$ using the Equation 1.

$$
\text { Water productivity }=\frac{\text { Yield }(\mathrm{kg} / \mathrm{ha})}{\text { Water used through out season }(\mathrm{mm})} \quad \text { Equation } 1
$$

\section{RESULTS AND DISCUSSION}

The zero origin (1:1) graphs of the relationship between simulated and observed data illustrate that APSIM has simulated observed yields for short age (Bg300) and medium age (Bg359) rice varieties with a high accuracy (Fig. 1). The CV was $14 \%$ and $8 \%$ and RMSE was 645 and 357 for $\mathrm{Bg} 300$ and $\mathrm{Bg} 359$, respectively. A CV value less than 20\% is generally considered as good fit of models (Mahdian and Gallichand, 1995; Antonopoulos, 1997; Olivares and Forero, 2010). Therefore, the parameterized model for Bg300 and Bg359 could be used to analyze the yield performances of those varieties irrespective of the season under local conditions and different scenarios. 

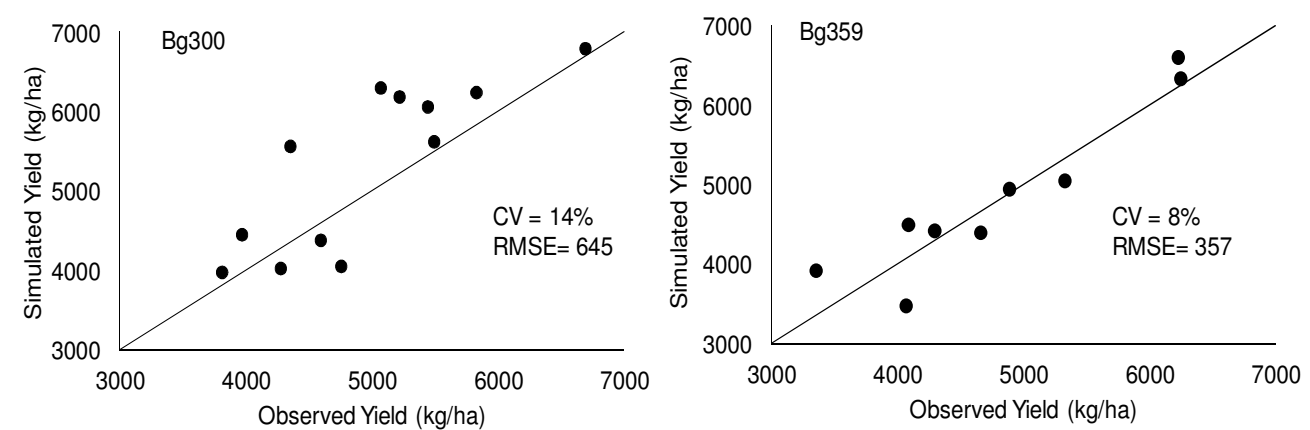

Fig. 1. Observed and simulated yield of $\mathrm{Bg300}$ and $\mathrm{Bg359}$ rice varieties grown during Yala and Maha seasons at Maha-Illuppallama, Sri Lanka

\section{Scenario analysis}

The analysis of rainfall data for the past 35 years (1976-2011) indicated that the onset of rains in the Maha season for Maha-Illuppallama area is between 37 to 44 standard weeks (September 13 to November 2; Table 2).

Table 2. Changes in the onset of Maha rains from 1976-2011

\begin{tabular}{lcc}
\hline Standard week & Onset week & No. of years \\
\hline $37,38,39$ & Sep 13 - Oct 2 & 10 \\
40,41 & Oct $3-$ Oct 14 & 14 \\
42,43 & Oct 15 - Oct 28 & 6 \\
44 & Oct 29 - Nov 2 & 5 \\
\hline
\end{tabular}

When the onset was early (Sep 13 - Oct 2) and an early planting could be practiced (i.e. Oct $11)$, a $33 \%$ higher yield $(3,900 \pm 120 \mathrm{~kg} / \mathrm{ha})$ was obtained when compared to that of the late planting (Nov 15; 2,600 $\pm 350 \mathrm{~kg} / \mathrm{ha}$ ) (Fig. 2). As the planting date delayed, the simulated yield was reduced and the lowest yield was evident at the most late planting. In contrast, when the onset was late (Oct 29 - Nov 2), the yield obtained at late planting (i.e. Nov-15) was $34 \%$ higher $(3930 \pm 200 \mathrm{~kg} / \mathrm{ha}$ ) when compared to that of early planting (i.e. Oct 11 , $2,600 \pm 600 \mathrm{~kg} / \mathrm{ha}$ ). Therefore, when the onset was delayed and planting was done earlier, the simulated yield was reduced (Fig. 2). Moreover, the variability of simulated yield was less when the onset and date of planting was matched (i.e. early planting at an early onset, and late planting at a late onset). Conversely, the variability was much higher when there was a disparity between the onset and planting date indicating a higher risk of obtaining lower yields. 


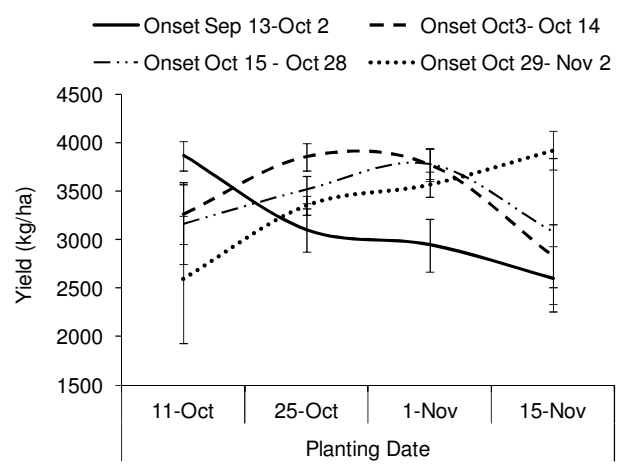

Fig. 2. Simulated rice grain yield of Bg300 at different planting dates with different onsets of seasonal rainfall

The $2^{\text {nd }}$ set of simulations showed that under conditions without water and nitrogen stress, the water productivity was lower while the yield obtained was higher, recording $4935 \mathrm{~kg} / \mathrm{ha}$ and $4620 \mathrm{~kg} / \mathrm{ha}$ for Oct 11 and Nov 15 sowings, respectively, than other scenarios (Fig. 3). The water productivity was higher when irrigation was withheld (i.e. rainfed-WI), however, the yield was lower $(3530 \mathrm{~kg} / \mathrm{ha}$ and $3020 \mathrm{~kg} / \mathrm{ha}$ for early and late sowings, respectively) (Fig. 3).
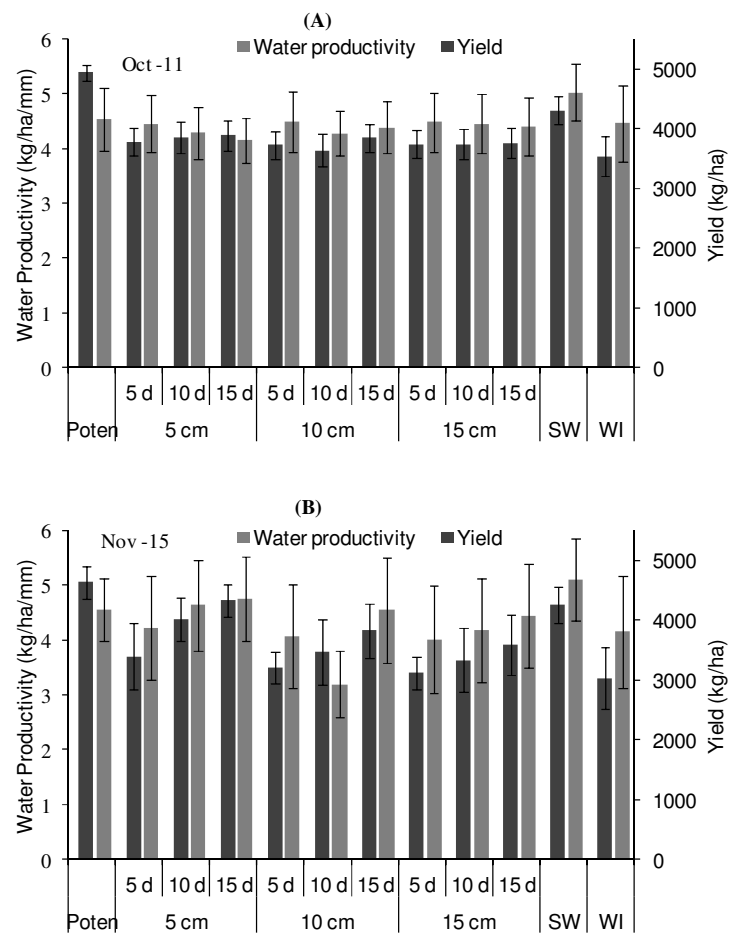

Fig. 3. Water productivity and simulated yield of rice with the change of irrigation amounts $(5,10,15 \mathrm{~cm})$ and intervals $(5,10,15$ days), and under rainfed condition (WI) for Bg300. SW was for $5 \mathrm{~cm}$ irrigation after $75 \%$ of the plant available water content was reduced. Poten is the APSIM-simulated potential yield (i.e. without moisture and nitrogen stresses). A: for early cultivation; B: for late cultivation 
At an early onset and early planting, the variability of water productivity and yield was less among the tested irrigation management options (i.e. changing the amount irrigated and timing of irrigation) (Fig. 3A) while a comparatively high variability was observed when the onset and planting was late (Nov-15) (Fig. 3B). Late planting with a late onset resulted a higher variability in water productivity $(4.3 \pm 0.34 \mathrm{~kg} / \mathrm{ha} / \mathrm{mm})$ when compared to that of early planting at an early onset $(4.4 \pm 0.12 \mathrm{~kg} / \mathrm{ha} / \mathrm{mm})$. Late planting at a late onset also resulted a higher yield variability $(3800 \pm 525 \mathrm{~kg} / \mathrm{ha})$ when compared to that of an early planting at an early onset $(3900 \pm 350 \mathrm{~kg} / \mathrm{ha})$. When the onset was early (i.e. Oct-11, Fig.3A), the yield variability and water productivity was less among the different irrigation management schedules of the rice variety $\mathrm{Bg} 300$. The APSIM-simulated potential yield $(4935 \mathrm{~kg} / \mathrm{ha})$ was $28 \%$ greater than the lowest yield simulated $(3535 \mathrm{~kg} / \mathrm{ha})$ indicating the importance of water limitations in this environment. However, when the onset was late (i.e. Nov-13, Fig. 3B), the variability in yield and water productivity was higher among different irrigation management schedules where the APSIM-simulated potential yield $(4620 \mathrm{~kg} / \mathrm{ha})$ was $35 \%$ higher than the lowest yield simulated (3020 kg/ha).

At a late onset, irrigating $15 \mathrm{~cm}$ of water at 5 day intervals resulted a higher yield (4330 $\mathrm{kg} / \mathrm{ha})$ and a higher water productivity $(4.7 \mathrm{~kg} / \mathrm{ha} / \mathrm{mm})$ when compared to the other irrigation management options tested (Fig. 3B). Therefore, appropriate irrigation management in years where there is a late onset is more important in achieving a higher yield and water productivity compared to that in the years with an early onset and early planting. Even though the irrigation management is difficult, if the practice is to apply irrigation water based on the soil water content than irrigating at a fixed/regular interval, the yield and water productivity obtained under SW at both early and late sowing was comparatively higher. Therefore, efficient water management practices in future should consider the soil water depletion patterns and prevailing weather conditions of a selected location or area.

Aligning planting date with respect to the onset of rainfall gives a substantial yield advantage when compared to the fixed date of planting strategy if the other conditions are satisfied (e.g. conducive temperatures and relative humidity during reproductive and maturity stages, minimum pest and disease occurrences). The atmospheric temperature and relative humidity during the reproductive and maturity stages are important as lower temperatures (17.0-19.5 ${ }^{\circ} \mathrm{C}$ ) increases grain sterility in rice ("Seethala bolweema") and reduce the yield (Abesiriwardena et al., 2002). Under the occurrences of highly variable weather conditions, particularly the irregularity of rainfall patterns, availability of a medium and long term rainfall forecast would help farmers to adjust their crop management practices, which will maximize the productivity of rice cultivation and water use.

\section{CONCLUSIONS}

Changing planting date of rice according to the onset of rainfall can reduce the irrigation water requirement and risk of rice cultivation. Early onset and an early planting resulted in a higher yield and water productivity across different irrigation management options, while there was a higher variability in both water productivity and yield at a late onset coupled with late planting with supplementary irrigation. Proper irrigation management, i.e. both timing and amount, is critical in obtaining higher water productivity when late planting is practiced. Therefore, decisions on timing of rice planting could potentially benefit from a forecast of the onset of seasonal rainfall, which may help reducing supplementary irrigation requirement during the Maha season. Irrigation management based on the soil water content than irrigating at a fixed/regular interval, resulted in a higher yield and water productivity. 
Therefore, efficient water management practices in rice cultivation should consider the soil water depletion patterns and weather.

\section{ACKNOWLEDGEMENTS}

The financial assistance provided by the AusAID-CSIRO project on "Can seasonal climate forecasting enhance food security in Indian Ocean rim countries" (AusAID Agreement 59553) through the Agriculture Education Unit (AEU) of the Faculty of Agriculture, University of Peradeniya, Sri Lanka is gratefully acknowledged. The authors also wish to acknowledge the support extended by the Natural Resources Management Centre (NRMC) and the Field Crops Research Development Institute (FCRDI) of the Department of Agriculture, Sri Lanka.

\section{REFERENCES}

Abesiriwardena, D.S.D.Z., Ohba, K. and Muruyama, A. (2002). Influence of temperature and relative humidity on grain sterility in rice: Journal of national science foundation in Sri Lanka. 30, 33-41.

Antonopoulos, V.Z. (1997). Simulation of soil moisture dynamics in inrrigated cotton in semi-arid climates. Agricultural Water Management. 34, 233-246.

Bouman, B.A.M., Kropff, M.J., Tuong, T.P., Wopereis, M.C.S., ten Berge, H.F.M. and van Laar, H.H. (2001). ORYZA2000: modelling lowland rice. Los Banos (Philippines): International Rice Research Institute, and Wageningen University. 235.

Chitranayana, R.D. and Punyawardena, B.V.R. (2010). Determination of onset time of rains during Yala and Maha seasons in major rice growing regions of Sri Lanka. Abstract of Papers. Proceedings Rice Congress 2010. Plant Genetic Resources Center, Peradeniya, Sri Lanka.

DCS (2011). Paddy Statistics, Annual report of the Department of Census and Statistics, Sri Lanka. [Online].

[http://www.statistics.gov.lk/agriculture/Paddy\%20Statistics/PaddyStats.htm (Accessed on 20.06.2013)

Heinemann, A.B., Pepijn, A.J., Oort, O., Fernandes D.S. and Maia, A.H.N. (2012). Sensitivity of APSIM/ORYZA model due to estimation errors in solar radiation. Congress of the European society for Agronomy. 71, 33-134.

http://www.apsim.info/Wiki/APSIM-Model.ashx. APSIM documentation, CSIRO, Australia [Online]. (Accessed on 10.06.2013).

http://www.agridept.gov.lk/index.php/en/crop-recommendations/808 [Online]. (Accessed on 12.05.2013)

Keating, B.A., Carberry, P.S., Hammer, G.L., Probert, M.E., Robertsona, M.J., Holzwortha, D., Hutha, N.I., Hargreaves, J.N.G., Meinke, H., Hochmana, Z., McLeanb, G., Verburgc, K., Snowc, V., Dimes, J.P., Silburne, M., Wang, E., Browna, S., Bristowc, K.L., Asseng, S., 
Chapmanb, S., McCowna, R.L., Reebairne, D.M.C. and Smith, J. (2003). An overview of APSIM, a model designed for farming systems simulation. European Journal of Agronomy. $18,267-288$.

Mahdian, M.H. and Gallichand, J. (1995).Validation of the SUBSTOR model for simulating soil water content.Transactions of the ASAE. 38, 513-520.

Mapa, R.B., Somasiri, S. and Dassanayake, A.R. (2010). Soils of the dry zone of Sri Lanka. Special Publication No. 7, Soil Science Society of Sri Lanka.

McKeon, G.M., Howden, S.M., Abel, N.O.J. and King, J.M. (1993). Climate change: adapting tropical and subtropical grasslands. In: Baker M.J. (Ed.) Grasslands for Our World, SIR Publishing, Wellington, NZ.

Olivares, A.M. and Forero, C.G. (2010). Goodness-of-Fit Testing, International Encyclopedia of Education. 7, 190-196.

Punyawardena, B.V.R. (2002). Identification of the potential of growing season by the onset on seasonal rains: the study in the DL1 region of the north central dry zone. Journal of the National Science Foundation of Sri Lanka. 30, 13-21.

Rathnayake, W.M.U.K. and Malaviarachchi, M.A.P.W.K. (2011). A crop simulation approach to determine optimum sowing dates for rainfed rice cultivation in the intermediate zone of Sri Lanka. In: Monograph on Rice Water Productivity in South Asia, SAARC Agriculture Centre. (In press)

Samuel, T.D.M.A. (1991). Estimation of global radiation for Sri Lanka. Solar Energy 47(5), 333-337.

Suriyagoda, L.D.B. and Peiris, B.L. (2011). Does reduced application of nitrogen topdressing affect grain yield of rice. In: Monograph on Rice Water Productivity in South Asia, SAARC Agriculture Centre. (In press).

Thiyagarajan, T.M. and Selvaraju, R. (2001). Water saving in rice cultivation in India: Proceedings of an international workshop on water saving rice production systems. Nanjing University, China, pp.15-45.

UNESCO-WWAP (2009). World Water Assessment Programme. The United Nations World Water Development Report 3: Water in a Changing World [Online]. [Accessed on 4.07. 2013] Available at

http://www.unesco.org/new/en/natural-sciences/environment/water/wwap/wwdr/wwdr3-2009/ 